\title{
Influence of Project Management in Requirement Engineering Process for Global Software Development
}

\author{
Tariq Aziz Rao \\ Department of Computer \\ Science \\ Virtual University of \\ Pakistan \\ Lahore, Pakistan
}

\author{
Ehsan-ul-Haq \\ Department of Computer \\ Science \\ Virtual University of \\ Pakistan \\ Lahore, Pakistan
}

\author{
Sadia Tariq \\ Department of Computer \\ Science \\ Virtual University of \\ Pakistan \\ Lahore, Pakistan
}

\author{
Humera Batool Gill \\ Department of Information \\ Technology Bahauddin \\ Zakariya University, \\ Multan, Pakistan
}

\begin{abstract}
In the modern era, Global Software Development (GSD) has become a widespread trend in modern as well as in developing countries. Whereas, the failure velocity of GSD projects transpires that the project management in this context is not a straightforward process due to geological, sociocultural, temporal and organizational problems. Requirement Engineering (RE) is of utmost importance being the first action of SDLC, failure of which is the complete failure of the project. Global Software Development makes the Requirement Engineering more challenging due to cultural and geographical differences. This study explores the worth of project management in the RE process for Global Software Development. A two-phase framework is proposed for requirement engineering and then conducted a web as well as manual analysis and interviews of field experts to find out the validity of this proposed framework. Finally, the collected data is evaluated by utilizing the statistical gadget. Obtained outcomes show the noteworthy impact of the proposed framework in GSD environment. This paper can be helpful for practitioners and researchers for future exploration in the GSD field.
\end{abstract}

\section{Keywords}

Global software development, requirements engineering, requirements engineering process

\section{INTRODUCTION}

The development of high-quality product in lowest cost has always the priority of any software developing organization. Due to fierce competition and budgetary load, software companies are distributing their activities across national and global markets. This kind of software development in which team members belong to various countries is acknowledged as Global Software Development.

In the present era, GSD is a growing trend due to the production of the optimum quality product at low cost. On the other hand, GSD faces a lot of challenges due to several differences such as geographical, socio-cultural, organizational and temporal that obstruct in the implementation of these projects and management. Due to cultural, native language and time differences, team members have limited interaction amongst them. So, they have the partial prospect of coordination, trust building, and collaboration. In a distributed environment, sometimes projects fail due to the absence of efficient management. However, an efficient project management plan can cater this coordination gap.

The first activity of SDLC is Requirement Engineering that describes the customers' problems and determines their expectations, which is valuable in the provision of the specification to developers, as well as designers to build the desired project. Requirement engineering is a difficult task due to the involvement of different stakeholders, various customers' requirements and poor requirement management. In a distributed environment, these problems are more aggravated; therefore, the importance of requirement engineering cannot be neglected. However, better communication is played a vital role in producing the desired product at affordable cost but the communication is reserved in distributed development as the team members are connected with each other via email, phone calls and video conferencing, etc.

There is a dire need to propose a strong framework of requirement engineering while implementing the GSD environment in order to collect and analyze the real requirements. Furthermore, an appropriate framework maintains a precise way to deal with the data among the project team personnel and others that contribute to the project improvement. Software management is not an easy task but it is much more difficult especially when performed in the distributed environment, therefore, software managers must be expert in their domains to face any internal stages' complications and for better software management. Therefore, the communication problem must be addressed in global software development during developing the framework of requirement engineering.

This manuscript is arranged as follows: Section II explains the knowledge obtained from literature review, problem statement is defined in Section III, Section IV presents the proposed framework, Section V describes the research methodology, Section VI exposes the statistical investigation of survey and interviews, Section VII provides the conclusion of this research and future work

\section{LITERATURE REVIEW}

The majority of the software companies have already started the software development in a distributed environment with the advent of cheap, high speed and reliable communication but about $40 \%$ of GSD projects were failed in providing the desired results [1]. Inefficiently managed the GSD projects is one of the major cause of failure. Authors described the challenges facing by the project management due to poor communication, collaboration, and coordination. Furthermore, socio-cultural, organizational and geographical distances are also affected the project management. They also proposed a framework for GSD projects in order to minimize these issues. The pure and complete requirements gathering and requirement management are vital and intricate actions in the Software Development Life Cycle (SDLC). Effective 
communication is a very prosperous activity in requirement engineering process. Authors proposed a three-phase framework of Requirement Engineering (RE) and Requirement Change Management (RCM) for GSD [2]. They also suggested that a specialist project manager for each phase can efficiently redress the issues in RE and RCM.

Niazi et al disclosed that the project manager's skills, organizational structure collaboration, and communication factors played an important job in the success of any GSD organization [3]. In 2018, authors conducted a detailed analysis and survey of many software companies of Pakistan and described the major challenges in the RE process [4]. They proposed a customized specification model, which is helpful to understand the gap in the RE process of software organization of Pakistan as well as other growing states. A literature-based evolution of requirement engineering process and problems related to GSD are discussed by the authors [5]. On the basis of results obtained after analysis, they highlighted the gaps and paucities in the present global software development based on requirement engineering process models. In a case study, authors implemented 12 software development projects within the same company and concluded that changes are always taking place in projects regardless of the selected software development methodology and project success does not always depend only on the quality of requirement elicitation process, as the customer interviews can be equally useful in any software development methodology [6].

Authors presented the outcomes of a systematic mapping study after reviewing of 104 papers published between the years 2001 and 2017 and identified the obstacles facing by the practitioners while dealing with requirement engineering in agile context [7]. They concluded that the field of R.E is broad in agile context and still immature and required further investigation. During analysis, they found one obstacle correlated to the environment, 5 obstacles linked to people and 5 obstacles associated with resources. Authors proposed a framework that facilitates the organization to efficiently manage the requirement engineering problems into different levels [8]. Authors conducted a systematic literature review (SLR) and disclosed that virtual teams are helpful for software organization in achieving various benefits like cost, time and skillful resources [9]. On the other hand, their study results show that ineffective communication cultural differences, bed IT infrastructure, and geographical distance are the key issues that must influence the victorious maneuver in virtual groups.

Akbar et al performed the arithmetical comparisons for the effect of heavyweight and lightweight methodologies on every factor of six-pointed star model (time, product, resource, cost, quality and risk) and concluded that the lightweight methodologies are appropriate for small-scale projects, whereas, heavyweight provides the improved result for large and medium projects [10]. Traditional to agile approaches are utilized by the organization for software development. Authors made a survey of project managers and software engineering team members regarding their utilization of software development methods and concluded that the scrum and agile unified process are more common [11]. Whereas, hybrid approaches are also being used for software development but the choice of methods is based on particular organizational and project traits. Coordination, cooperation, and communication features directly influence the effort estimation of a project [12].

\section{PROBLEM STATEMENT}

A number of requirements engineering models are being utilized by the software organizations but no unified model is currently available for execution in organizing the requirements while preparing a software product in a distributed environment. In June 2018, Shafiq et al proposed a framework of RE and RCM for GSD [2]. According to their proposed 3-phase model of R.E, phase-wise selection of Software Manager is more suitable to redress the issues in GSD. However, after a systemic literature review of published papers, it transpired that more phase-wise appointment of Project Manager may be increased the financial cost where numerous challenges are already facing by the organization in GSD. Effective and timely communication played an important role in acquiring the real requirements. In GSD, an environment is geographically distributed, so, there is no faceto-face communication and absence of which may lead to the misunderstanding and disagreement among the stakeholders. Therefore, there is a dire need to develop an appropriate framework of R.E which not only redresses the grievances faces in GSD environment but also cost-effective.

\section{PROPOSED FRAMEWORK}

Project management always played a vital role in the successful implementation of any framework. After the literature review, it transpired that various project management techniques are available but the importance of the project manager cannot be ignored. The proposed framework of RE for GSD is split up into two phases to achieve the best results, as shown in Fig 1 .

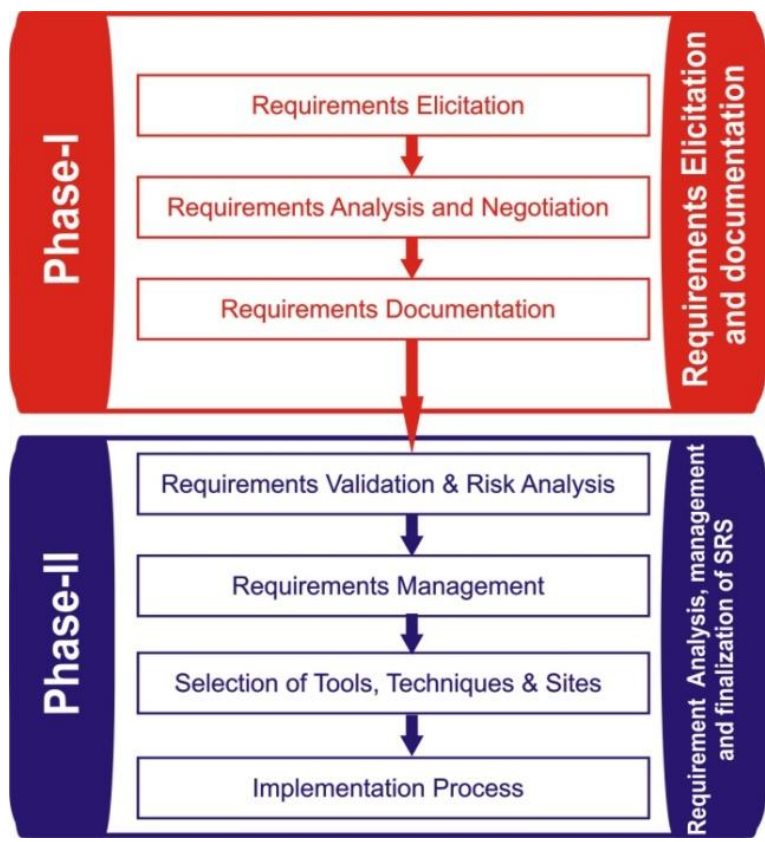

Fig 1: Proposed framework of RE for GSD

The $1^{\text {st }}$ phase of the proposed formwork is the requirements elicitation and documentation, which consist of the requirements elicitation, requirements analysis and negotiation, and requirements documents. In this phase, customers' requirements, and their expectation are collected through interviews and site visits, etc. and necessary questions may also be asked to clear all the ambiguities. After detail discussion during interviews, analyzed requirements should be documented. The project manager of this phase must be a professional with interpersonal skills, customer service 
proficiency and other technical abilities to efficiently manage this phase.

Requirements Analysis, management, and finalization of SRS is the $2^{\text {nd }}$ phase of the projected model that include the requirements validation and risk analysis, requirements management, selection of tools/techniques/sites, and implementation process to finalize the SRS. Project Manager of this segment should have the ability to manage all such activities in a well-organized manner.

\section{RESEARCH METHODOLOGY}

In order to validate the proposed framework of Requirement Engineering, manual as well as a digital survey at national as well as international level and interviews of market specialists in Pakistan were conducted. Few local software houses were personally visited, whereas, some were contacted through mobile phone, Whatsapp and Facebook Messenger call to conduct the interviews of domain experts who have a sufficient experience in Global Software Development. Project Managers and Requirement Engineers from famous multinational development organizations participated in these interviews. City-wise interviews response is shown in Figure 2.

\section{City Wise Response of Interviews}

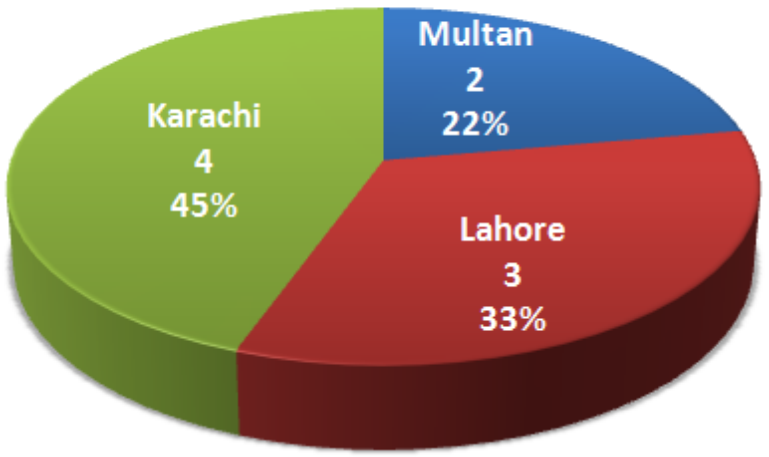

Fig 2: City-wise response of interview for RE framework

For an effective survey, a questionnaire consisting of 29 queries ( 8 related to Answerer's personal information while 11 related to different factors influence by the R.E framework) was prepared and 5-point Likert scale was used. The survey was executed through two approaches, such as manual survey and web-based survey. The actual intention of the manual survey is to acquire the factual picture after the accomplishment of this proposed framework, whereas, the intention of the web survey is to obtain the common view of the domain experts.

During these surveys, requirement engineers, project managers and analysts who are associated with the RE process in GSD are the main target personalities from various countries. In order to conduct the survey from all over the world, initially friends and relatives in various countries were requested to send the requisite survey to GSD professionals and a copy of the same may also be sent to their contact links for similar necessary action. Social media friends were also requested to render their assistance in this regards. Resultantly, a reasonable response was received which is shown in Figure 3(a) \& 3(b).

\section{City Wise Response of Manual Survey}

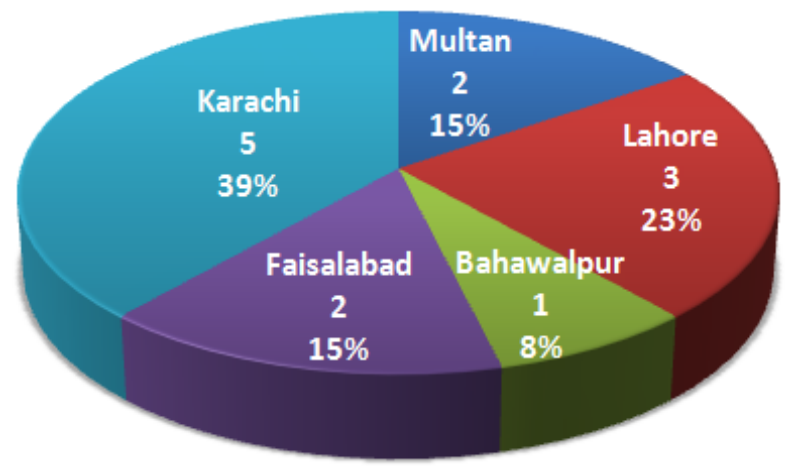

Fig 3 (a): City-wise response of manual survey for RE framework

\section{Country Wise Response of Web Survey}

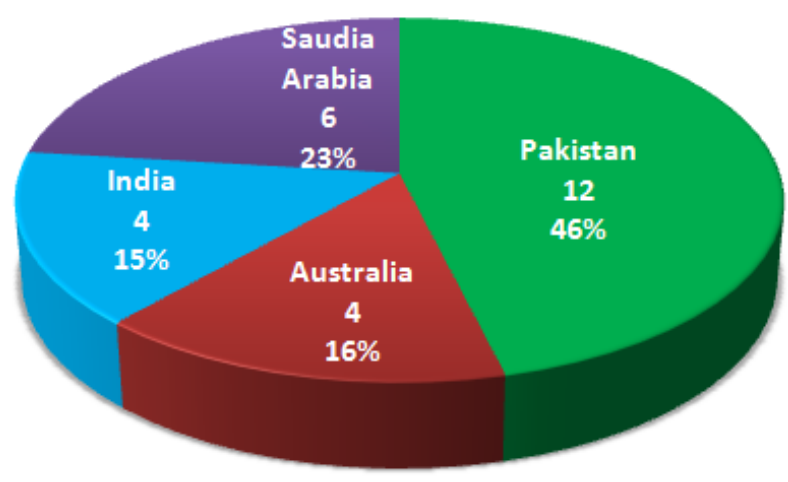

Fig 3 (b): Country-wise response of web survey for RE framework

\section{STATISTICAL ANALYSIS OF SURVEYS AND INTERVIEWS}

During these surveys, answerers' responses consisting of Q9 to Q29 regarding the proposed framework of R.E were considered. After utilizing the statistical gadget (MS Excel), obtained results were finalized, detail of which is given as under: -

\subsection{Interview Results}

In order to examine the suitability of the proposed framework of RE, interviews were conducted. Technical questions were asked during this process and their responses were recorded. The impact of the projected RE framework on all the factors (scope, scheduling, cost, quality, resources, communication, risk, stakeholder) of project management is remarkable. Interview results regarding the proposed framework of RE are shown in Figure 4.

\subsection{Manual Survey Results}

The actual purpose of a manual survey is to obtain the real picture of RE framework after its implementation. The manual survey results are shown in Figure 5.

\subsection{Web Survey Results}

A better response was received through a web survey which is shown in Figure 6. Obtained results reflect that the proposed framework of requirement engineering with dedicated project 
management is played a vital role in obtaining complete and real requirements.

\subsection{Comparative Analysis of results obtained after conducting Interviews, Manual Survey and Web Survey}

In last, a comparative analysis of results obtained after conducting interviews, manual survey, and web survey is made, results of which are shown in Figure 7.

\subsection{Influence of Project Management in the RE process}

After collection of data from all the resources, it transpired that

- Experience of Project Managers is played a vital role in the requirement engineering process.
- $\quad$ Phase-wise selection of Project Manager is helpful for the timely release of the project.

- Appointment of Project Manager is purely made on his/her expertise in a relevant field and geological and language differences kept in mind during the selection process.

It reveals from the interviews, manual and web survey that, if phase-wise dedicated project management modus operandi is deployed in the proposed framework, the activities of RE will provide the better results which not only increase the success rate of the project but also provide the optimum quality product. The role of project management in RE is shown in Figure 8 .

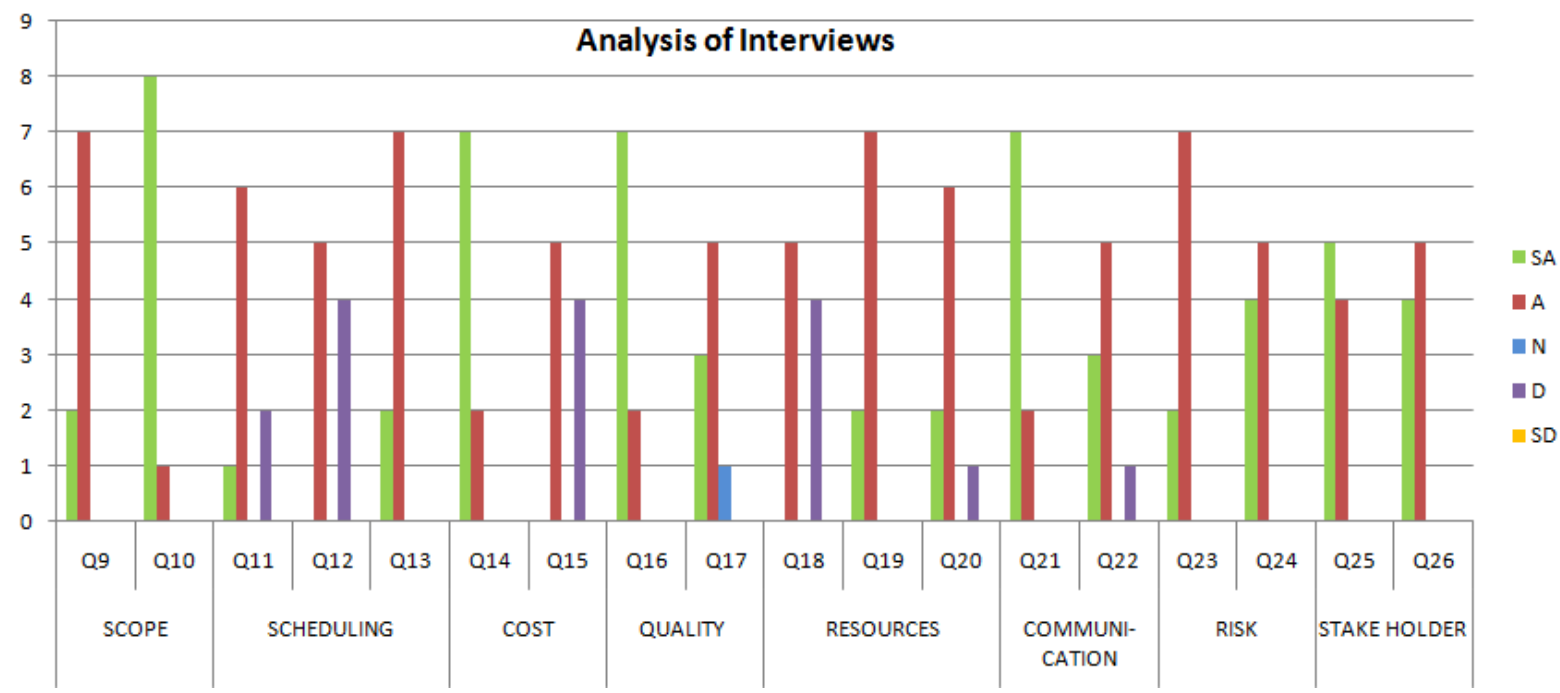

Fig 4: Frequency analysis of interviews regarding proposed framework of RE

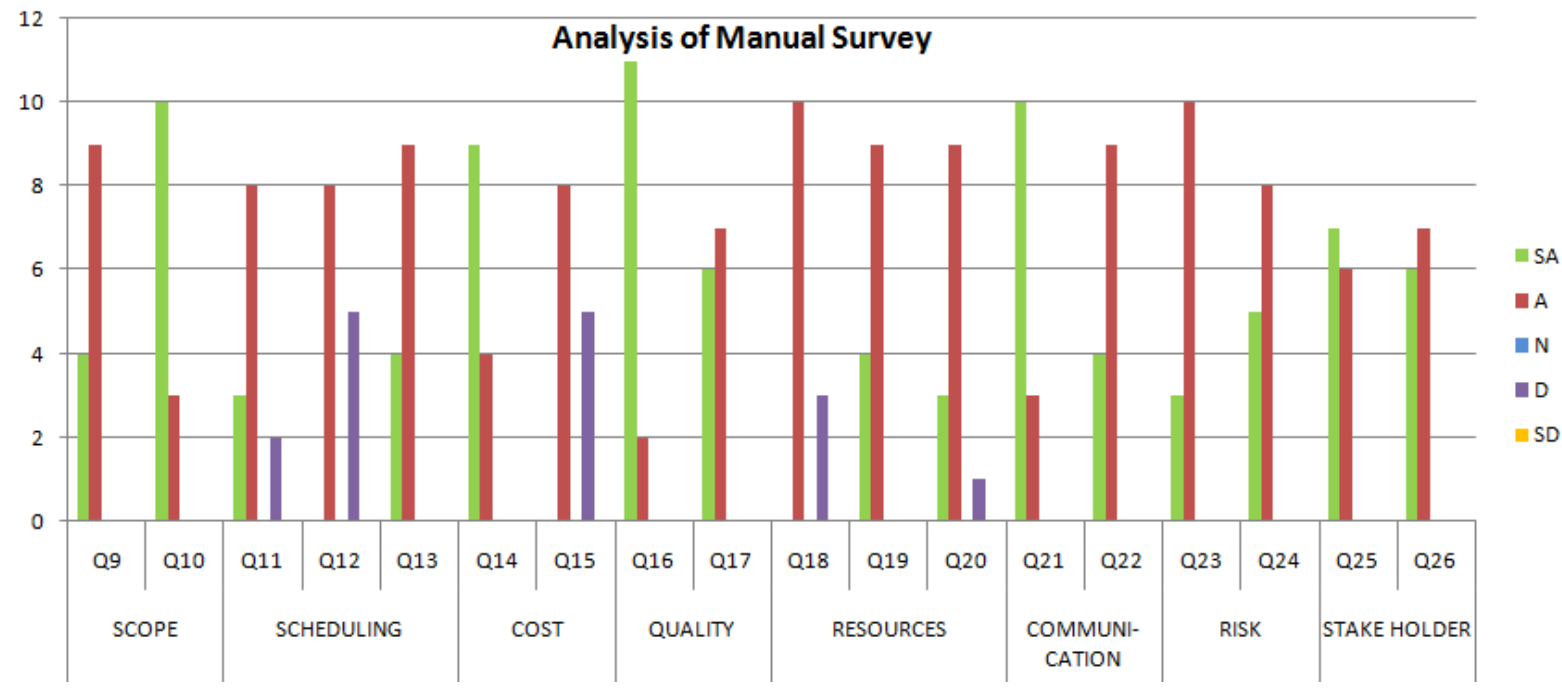

Fig 5: Frequency analysis of manual survey regarding proposed framework of RE 


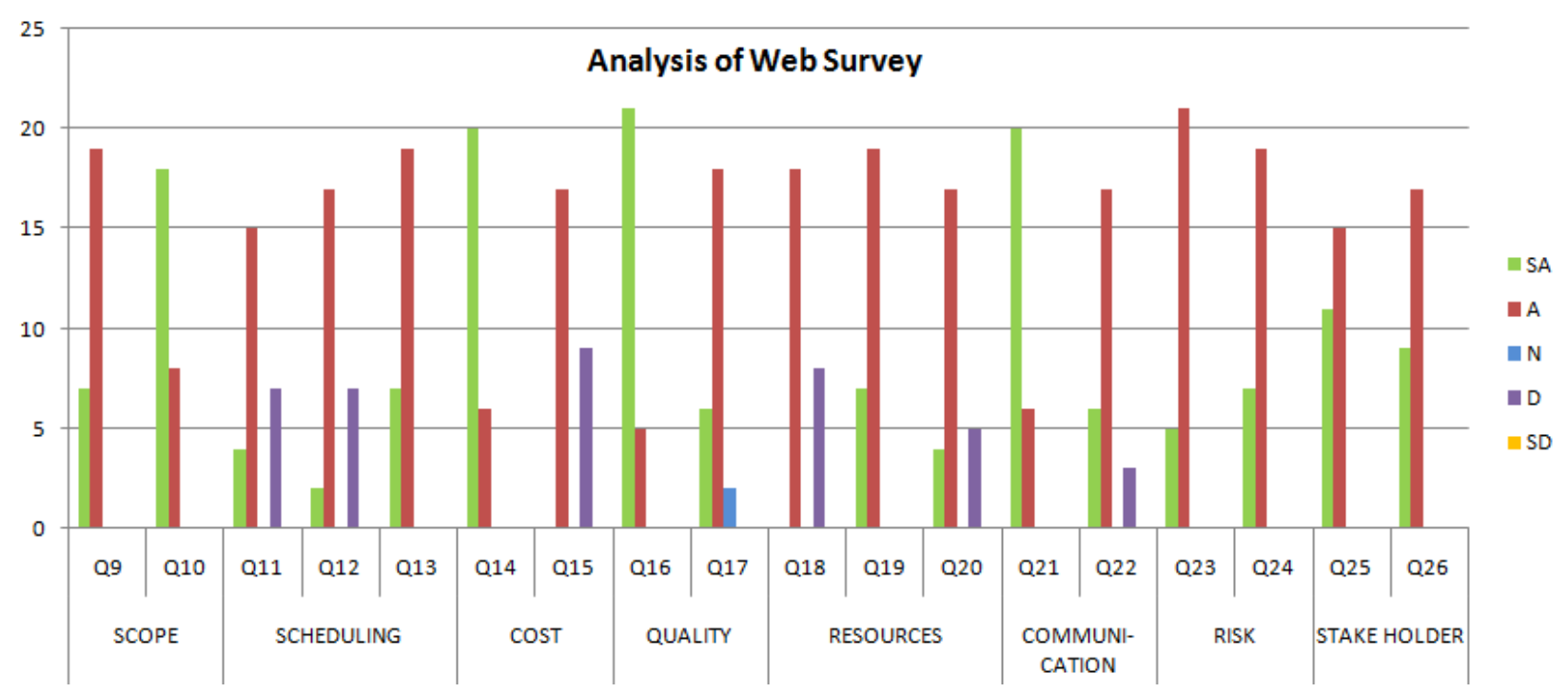

Fig 6: Frequency analysis of web survey regarding proposed framework of RE

Comparison of Interview, Manual and Web Survey

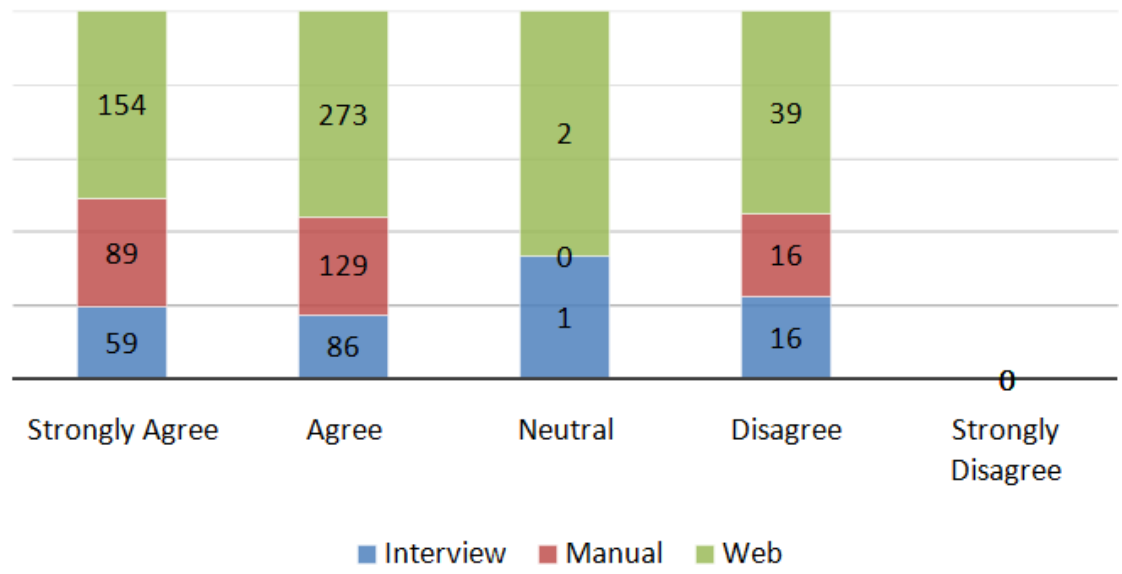

Fig 7: Comparison of interviews, manual and web survey

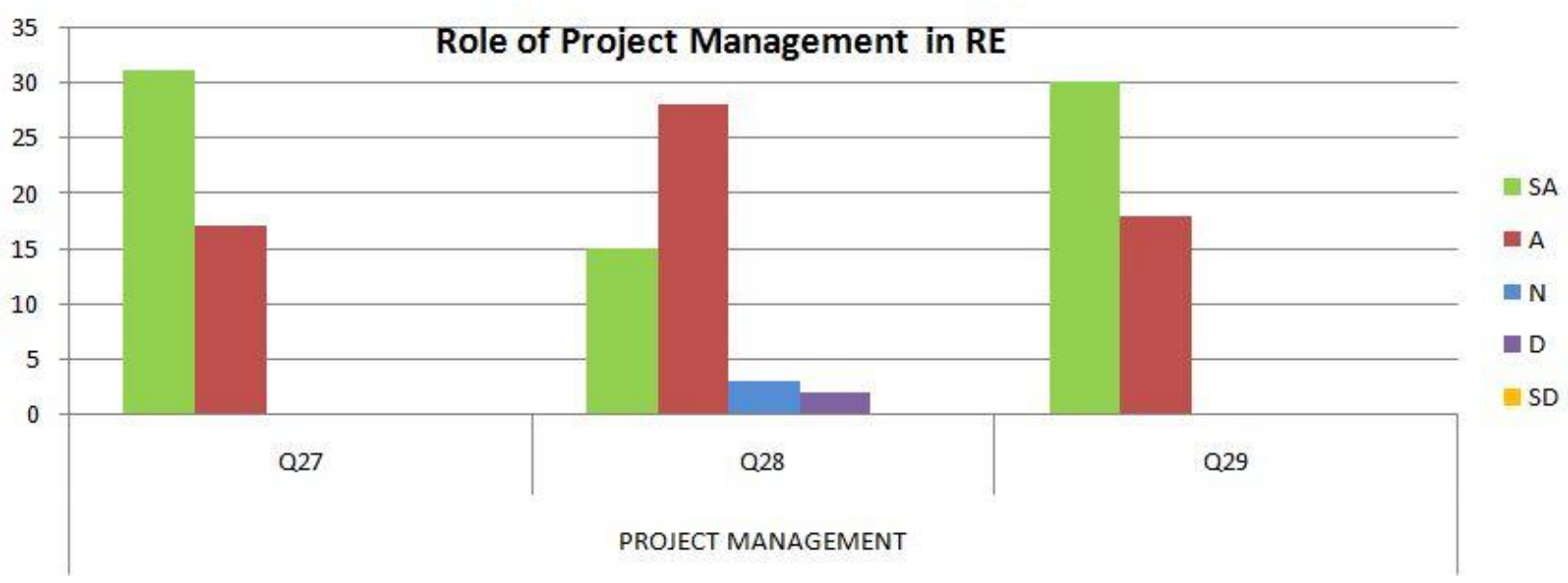

Fig 8: Role of Project Management in RE 


\section{CONCLUSION AND FUTURE WORK}

Inadequately defined and executed requirement engineering process may lead to the production of low-quality products at an elevated cost that not only cause of financial loss to the organization but also defames its reputation. In this paper, we proposed a framework of Requirement Engineering for Global Software Development in order to eradicate or at least reduce the communication, collaboration and management challenges in GSD environment due to organizational, socio-cultural, temporal and geographical distances. Phase-wise selection and expertise of project manager are helpful for managing these challenges facing during the requirement gathering, analyzing the risk factor, project management, selection of tools and sites and finalization of SRS especially in GSD environment and timely delivery of the project.

In the future, the area as well as the time span of these surveys will be expanded to acquire the optimum results after further deployment of this framework in GSD environment. However, this study will be helpful for practitioners and researchers for future investigation the influence of project management in Requirement Engineering for GSD.

\section{APPENDIX (QUESTIONNAIRE)}

See Section 1-2

\section{Section 1: Answerer's Profile}

1 Gender

Male

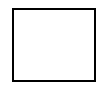

Female

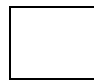

Post in Organization

CEO

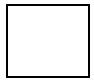

Project Manager

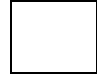

Requirement Engineer

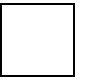

Designer

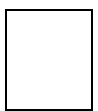

Coder

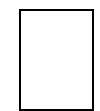

Other

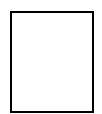

Analyst

Master

Ph.D

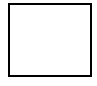

Intermediate

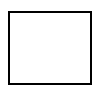

Matriculate

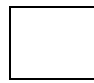

Diploma Holder

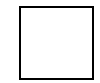

Other

Under Graduate

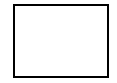

Graduate
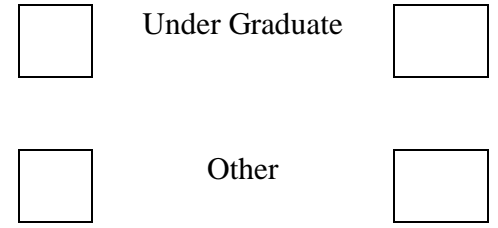

$4 \quad$ Your working experience

$$
1-2 \text { years }
$$

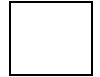

$3-5$ years

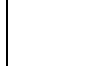

$6-10$ years

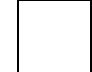

More than 10 years

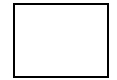

5

Your organization is developing what kind of application

Desktop Applications

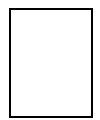

Web-based

Applications

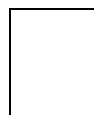

Desktop \& Web

Applications

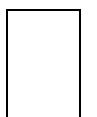

Others

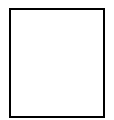

6 Number of Software Developers working in your organization

$$
1-10
$$

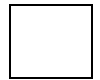

$11-20$

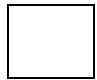

$21-50$

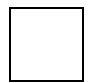

Above 50

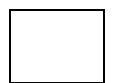

7 Is the specialization of Requirement Engineer is a key of success of any project

Highly Agree
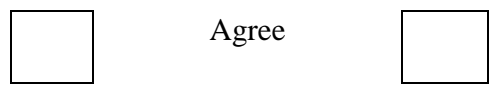

Disagree

Strongly Disagree

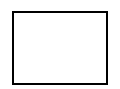


How you find the proposed framework

Best

Satisfactory

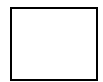

$\mathrm{Bad}$
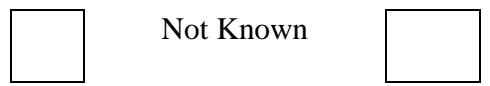

Section 2: Answerer's response regarding Framework of Requirement Engineering

\begin{tabular}{|c|c|c|c|c|c|c|c|}
\hline FACTOR & & QUESTION & SA & $\mathbf{A}$ & $\mathbf{N}$ & D & SD \\
\hline \multirow{2}{*}{ 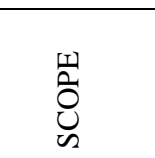 } & 9 & The scope of demanded requirements are well-described & & & & & \\
\hline & 10 & $\begin{array}{l}\text { Effective Project Management is essential to acquire the wholesome } \\
\text { requirements }\end{array}$ & & & & & \\
\hline \multirow{3}{*}{ 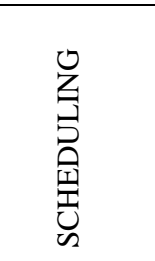 } & 11 & Team members are timely realize the importance of requirements collection & & & & & \\
\hline & 12 & Team members are satisfactorily and timely collected the users' demands & & & & & \\
\hline & 13 & $\begin{array}{l}\text { Proposed Framework of R.E is an effective strategy to timely acquire the } \\
\text { complete requirements }\end{array}$ & & & & & \\
\hline \multirow{2}{*}{ 㫄 } & 14 & Requirement Engineering has a great impact on project's cost & & & & & \\
\hline & 15 & $\begin{array}{l}\text { Due to financial constraints, phase-wise selection of Project manager is } \\
\text { suitable }\end{array}$ & & & & & \\
\hline \multirow{2}{*}{ 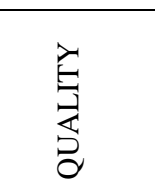 } & 16 & Quality of project must be affected due to poor requirement engineering & & & & & \\
\hline & 17 & Quality of project can improve by phase-wise selection of Project Manager & & & & & \\
\hline \multirow{3}{*}{ 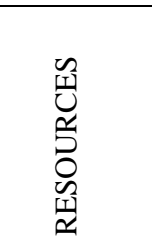 } & 18 & $\begin{array}{l}\text { Required resources for project development are mostly available during RE } \\
\text { Process }\end{array}$ & & & & & \\
\hline & 19 & Pure requirement collection can be made through team work & & & & & \\
\hline & 20 & Existing resources are fully utilized during the RE Process & & & & & \\
\hline \multirow{2}{*}{ 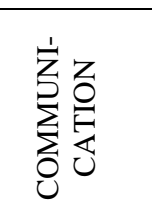 } & 21 & $\begin{array}{l}\text { Effective communication between Project Manager and customer played an } \\
\text { important role in success of project }\end{array}$ & & & & & \\
\hline & 22 & $\begin{array}{l}\text { Phase-wise selection of Project Manager is helpful for successful } \\
\text { communication in GSD }\end{array}$ & & & & & \\
\hline \multirow[b]{2}{*}{$\frac{v}{2}$} & 23 & Risk factors in RE Process are managed efficiently & & & & & \\
\hline & 24 & $\begin{array}{l}\text { Phase-wise selection of Project Manager is suitable in order to reduce the } \\
\text { risk factor }\end{array}$ & & & & & \\
\hline \multirow{2}{*}{ 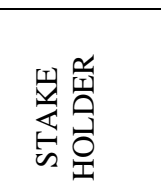 } & 25 & $\begin{array}{l}\text { There is a dire need of identification of stakeholders and analyzing their } \\
\text { expectations }\end{array}$ & & & & & \\
\hline & 26 & $\begin{array}{l}\text { Proposed framework of R.E is more effective for identification of } \\
\text { stakeholder and analyzing their expectation }\end{array}$ & & & & & \\
\hline \multirow{2}{*}{ 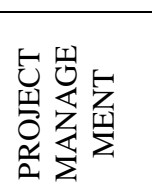 } & 27 & $\begin{array}{l}\text { Experience of Project Managers is played a vital role in requirement } \\
\text { engineering process }\end{array}$ & & & & & \\
\hline & 28 & Phase-wise selection of Project Manager is helpful for timely release of the & & & & & \\
\hline
\end{tabular}




\begin{tabular}{|l|l|l|l|l|l|}
\hline & project & & & & \\
\cline { 2 - 5 } & 29 & $\begin{array}{l}\text { Appointment of Project Manager is purely made on his/her expertise in the } \\
\text { relevant field, and geological and language differences also kept in mind } \\
\text { during selection }\end{array}$ & & & \\
\hline $\begin{array}{l}\text { ANY OTHER } \\
\text { COMMENTS }\end{array}$ & & & \\
\hline
\end{tabular}

SA = Strongly Agree, A=Agree, $N=$ Neutral, $D=$ Disagree, $S D=$ Strongly Disagree

\section{REFERENCES}

[1] Jain, R. and Suman, U. 2018. A Project Management Framework for Global Software Development. ACM SIGSOFT Software Engineering Notes, vol. 43, no.1, pp. $1-10$.

[2] Shafiq, M., Zhang, Q., Akbar, M. A., Khan, A. A., Hussain, S., Amin, F., Khan, A. and Soofi, A. A., May, 2018. Effect of Project Management in Requirements Engineering and Requirement Change Management Processes for Global Software Development, IEEE Access, vol.6, pp. 25747-25763.

[3] Niazi, M., Mahmood, S., Alshayeb, M., Qureshi, A. M., Faisal, K. and Cepra N. August, 2016. Towards successful project management in global software development. International Journal of Project Management, vol.34, no.8, pp. 1553-1566.

[4] Riaz, M. Q., Rehman, F., Maqbool, B. and Butt, W. H. 2018. Customization of Requirement Engineering Best Practices for Pakistan Software Industry. In IEEE International Conference on Computing, Mathematics and Engineering Technologies - iCoMET, pp. 15531567.

[5] Javed, B. and Minhas, S. S. 2010. Process support for Requirement Engineering activities in Global Software Development: A literature based evaluation. In IEEE International Conference on Computational Intelligence and Software Engineering.

[6] Bormane, Grzibovska, J., Berzisa, S. and Grabis, J. December, 2016. Impact of Requirement Elicitation Processes on Success of Information Systems
Development Projects. Information Technology and Management Science, vol.19, pp. 57-64.

[7] Curcio, K., Navarro, T., Maluelli, A. and Reinehr, S. 2018. Requirements Engineering: A systemtic mapping study in agile software development. The Journal of Systems and Software, vol.139, pp. 32-50.

[8] Kumar, S. A. and Kumar, T. A. October, 2011. Study the impact of Requirement Management Characteristics in Global Software Development Projects: A Ontology based approached. International Journal of Software Engineering \& Applications (IJSEA), vol.2, no.4, pp. 107-125.

[9] Shameem, M., Kumar, C. and Chandra, B. 2017. Challenges of Management in the Operation of Virtual Software Development Teams: A Systematic Literature Review. In IEEE $4^{\text {th }}$ International Conference on Advance Computing and Communication Systems (ICACCS), pp. 1-8.

[10] Akbar, M. A., Sang, J., Khan, A. A., Amin, F., Nasrullah, Hussain, S., Sohail, M. K. Xiang, H. and Cai, A. B. March, 2018. Statistical Analysis of the Effect of Heavyweight and Lightweight Methodologies on the SixPointed Star Model. IEEE Access, vol. 6, pp. 8066-6079.

[11] Vijayasarathy, L. R. and Butler, C. W. October, 2016. Choice of Software Development Methodologies - Do Project, Team and Organizational Characteristics Matter. IEEE Software, vol. 33, no. 5 .

[12] Britto, R., Freitas, V., Mendes, E. and Usman, M. 2014. Efforts Estimation in Global Software Development: A Systematic Literature Review. In IEEE $9^{\text {th }}$ International Conference on Global Software Engineering, pp. 18-21. 